\title{
Observaciones en torno al origen y difusión de la cerámica de Miranda (Avilés)
}

\author{
Observations on the origin and distribution of pottery from Miranda (Avilés)
}

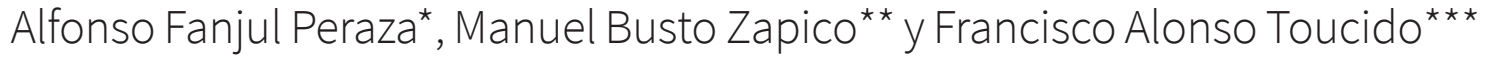 \\ Recibido: 12/4/2018 - Aprobado: 4/9/2018
}

\begin{abstract}
RESUMEN
A través de la revisión de las colecciones cerámicas de diversas excavaciones arqueológicas en Asturias y Galicia, proponemos algunos aspectos que puntualizan con mejor definición la evolución de la cerámica de Miranda. Al igual que en otros centros productores asturianos, el simple análisis etnográfico o documental era insuficiente sobre todo a la hora de trazar los orígenes o certificar algunos aspectos de esa producción artesanal sin la consiguiente revisión arqueológica. Nuestra revisión demuestra la existencia de unas primeras producciones preespecializadas de Miranda en la Baja Edad Media, con un surgimiento de las producciones claramente tradicionales en el siglo XVI.
\end{abstract}

Palabras clave: Etnoarqueología, Cerámica, Miranda, Baja Edad Media, artesanía.

\section{Introducción}

Uno de los problemas a la hora de definir la evolución de la cerámica asturiana, incluyendo sus principales producciones dentro de la denominada cerámica tradicional, lo constituye la falta de investigaciones arqueológicas, que nos ayuden a ir componiendo la secuencia material de los diferentes alfares. En los últimos años la comprobación de las diferentes hipótesis mediante excavaciones arqueológicas ha ayudado a definir un primer origen de la cerámica de Faro en el siglo XII (Fanjul et alii 2013; Fanjul 2017), así como a

\begin{abstract}
Based on a review of pottery collected from various archaeological sites in Asturias and Galicia, we present information that more accurately defines the development of pottery from Miranda. As in the case of other manufacturing workshops in Asturias, fundamental ethnographic and documentary analysis proved insufficient for tracing initial developments and confirming certain production characteristics, without a corresponding archaeological review. Our review demonstrates that early pottery from Miranda, before product specialisation, dates to the Late Middle Ages, and that distinctly traditional production emerged in the sixteenth century.
\end{abstract}

Key words: Ethnoarchaeology, pottery, Miranda, Low Middle Ages, art-craft.

abrir la puerta a un origen pre-contemporáneo para las producciones de Llamas del Mouro (Fanjul 2013; Fanjul y Tobalina 2016). En el caso de la cerámica de Miranda, el otro gran centro productor de cerámicas tradicionales, consideramos que la falta de excavaciones arqueológicas pueden ser suplidas con un primer estudio de las diversas colecciones materiales cerámicas recuperadas en actuaciones arqueológicas urbanas (Fanjul y García 2008), siempre bajo un denominador común, la correcta definición cronológica asignada a los diferentes niveles estratigráficos de donde proceden esas cerámicas.

* Arqueólogo. ${ }^{* *}$ Investigador de doctorado. Departamento de Arte de la Universidad de Oviedo. ${ }^{* * \star A r q u e o ́ l o g o . ~}$ 
Las características que definen las producciones de Miranda de Avilés y que permiten diferenciarlas de otros centros cerámicos, como podría ser Faro de Limanes, ya han sido enunciadas en diferentes trabajos (Feito 1985; Fernández y González 1989, 104-108; Busto 2015, 52-53). Además, también se han llevado a cabo estudios arqueométricos sobre su composición química que redundan en las diferencias entre Faro y Miranda (Busto et alii 2015). Por resaltar algunas de las características definitorias de las cerámicas de Miranda estas son la mica como desgrasante por excelencia, la cocción reductora y el acabado negro brillante conseguido mediante el bruñido de la pieza.

\section{Las producciones medievales pre- especializadas. Piezas de Miranda en la secuencia cerámica de Foncalada (Oviedo)}

La arqueología urbana de Oviedo no ha escapado a los problemas de la gestión arqueológica, que han afectado a otros ámbitos del patrimonio histórico regional desde los comienzos de las intervenciones de emergencia. De los dos centenares aproximadamente de intervenciones arqueológicas en la ciudad, tan solo una decena de las mismas ha sido publicada, mientras que la mayoría de esos estudios han desechado el material post-medieval al no considerarlo de interés documental. Por otra parte, se observa una potente falta de análisis, tanto de carbono 14, fauna, o estudios de carpología, lo que convierte la información del Oviedo arqueológico en un mero mapa de estructuras con cronologías aproximadas, en paralelo a la progresiva destrucción del casco histórico de la ciudad. Existen sin embargo excepciones positivas, donde sin la necesidad de coincidir en las interpretaciones finales, se constata un esfuerzo en documentar los diferentes niveles estratigráficos y sus materiales, pudiendo a día de hoy, proceder a revisiones de espacios históricos que en la mayoría de los casos ya no existen, a través de los informes de dichas excavaciones. En este sentido mostramos los datos de dos excavaciones urbanas de Oviedo de gran interés en cuanto al hallazgo de materiales cerámicos de Miranda, fechados además con gran precisión, caso de Foncalada (Estrada y Ríos 1995, 137). La fuente de Foncalada constituye la primera obra civil conocida de la monarquía asturiana y se considera Monumento Nacional desde 1931. Situada a 200 metros al Noroeste del Oviedo amurallado, la fuente dispone de un edículo rectangular de donde sale el agua, un canal de suministro, y un edificio exterior enmarcando el depósito a modo de piscina.

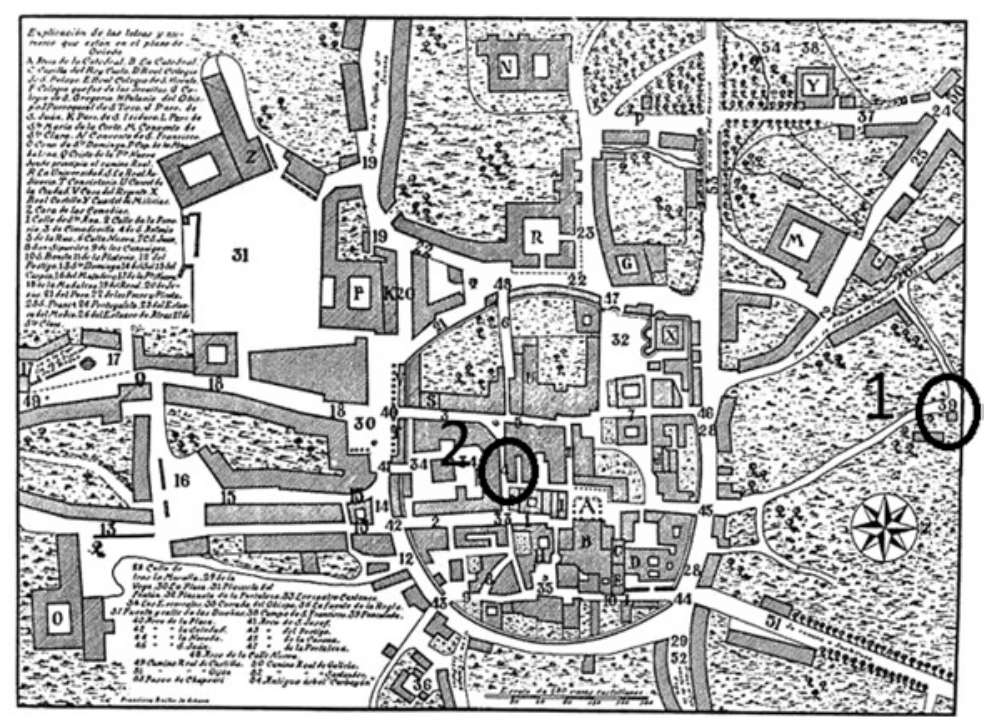

Mapa 1. Mapa de Oviedo de Reiter de 1777 donde ubicamos el solar de la Foncalada (1) y la calle San Antonio (2). 


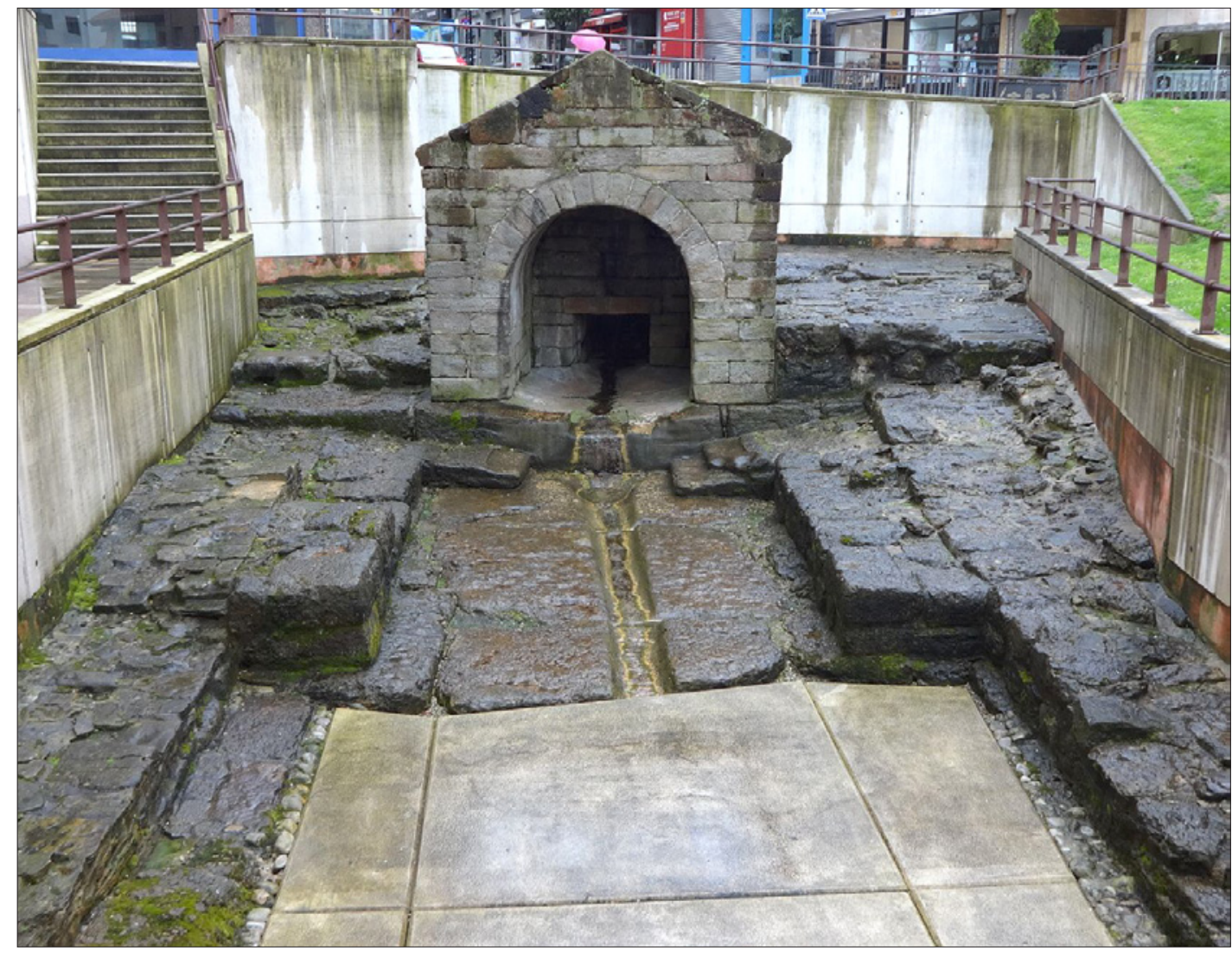

Fig. 1. Fuente de Foncalada en la actualidad.

Durante la primera fase de la investigación se realizaron 3 catas, la primera junto a la fuente, y las otras dos en la plaza exterior. Posteriormente se dividió toda la zona de actuación en sectores (central, Norte, Sur, Este y canal de suministro), dejando libre buena parte de la fuente original para su consolidación y apertura al público.

La secuencia estratigráfica puede parecer compleja, producto por un lado de las consecutivas ampliaciones de la excavación, así como por la existencia de numerosos niveles revueltos, si tenemos en cuenta que ha sido una fuente reutilizada desde la Edad Media al siglo XX. Sin embargo, las cronologías de cada unidad han sido muy bien definidas a través de una potente colección numismática analizada por Enrique Burguet Fuentes, lo que a través del siguiente esquema estratigráfico, producto de nuestra revisión, nos permite por un lado mostrar una evolución de la cerámica en Oviedo, y por otra parte, encajar las producciones de Miranda en esa secuencia.
NIVEL I a, I b, I c y I d - Niveles contemporáneos bajo el pavimento de la plaza formados por rellenos de escombro, gravas y canales de aguas fecales. La totalidad del material se adscribe entre los siglos XIX y XX.

NIVEL II a - Nivel arenoso de color rojizo con abundantes cantos y materiales mayoritariamente de finales de época Moderna aunque con algunos elementos contemporáneos como una moneda de 1830. Los horizontes cronológicos según el sector: Sector B4 - 1830, sector A1 - s. XVIII, sector cata 4 - finales del XVII al XVIII, sector 4 - siglo XIX.

NIVEL II b - Idéntico en composición al nivel anterior pero de color negruzco. La cronología de los materiales es similar al anterior aunque dependiendo del sector, ya se observan materiales propios del siglo XVI que llegan al XIX en sectores más revueltos. Los horizontes cronológicos según sector: Sector 4 - siglo XIX, cata 4 - siglos XVI-XVIII, sector A1 - siglo XVII, sector B4 - siglo XVIII. 
NIVEL III a - Formado por limos de color negruzco con cantos rodados y materia orgánica. Aunque se apunta la posibilidad de tener materiales desde el siglo XV, en la mayoría de los sectores estamos ante elementos de los siglos XVI-XVII. Los horizontes cronológicos según sector: Sector B4 - siglo XVII, sector A1 - siglo XVI, cata 4 - siglo XVI, sector A4 - siglos XVI-XVIII.
NIVEL III b - Espacio entre la roca madre y la rasante de usos de la fuente, producto de una limpieza del canal con abundante material cerámico medieval. Cronología del sector: Cata 4 - siglos XIII/XV.

Según esta secuencia, entre los siglos XIII y XV, la vajilla cerámica ovetense sigue domi-

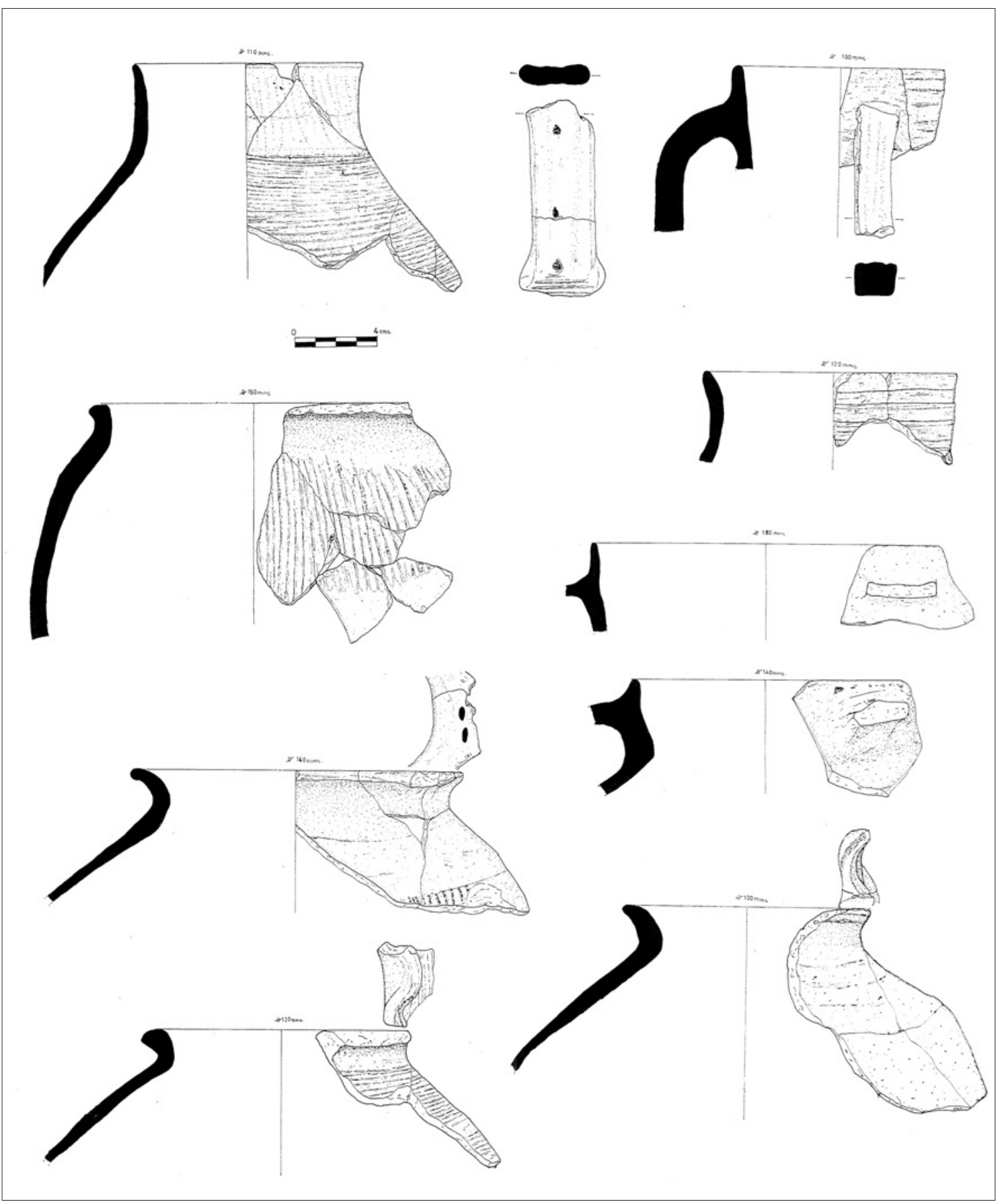

Fig. 2. Corpus de piezas cerámicas de los estratos Bajomedievales de Foncalada (Dibujos de las piezas procedentes de Estrada y Ríos 1995, modificados por nosotros para la realización de la figura). 
nada por el binomio jarra/olla. En el caso de las ollas estamos ante cocciones reductoras mientras que en las jarras dominan las oxidantes. Las bocas de las piezas se radicalizan buscando una mayor verticalidad en algunos casos, mientras en otros, los bordes planos se acercan en extremo a las panzas. Tanto las decoraciones reticuladas como las vidriadas (pieza 473, cata 4, nivel IIIb) son casi inexistentes, surgiendo en otras piezas molduras decorativas, producto de la potente profundidad y anchura de las líneas incísas horizontales.

Destacan dos aspectos muy característicos de la vajilla bajomedieval asturiana. Por un lado las ollas casi siempre aparecen incísas, a veces con líneas horizontales y en otros casos exclusivamente verticales, mientras que muchas de las asas están profundamente decoradas a punzón. Aquellas sin punzón forman una destacada nervadura central o lateral.

Entre los siglos XVI y XVII Ilegan con fuerza las lozas importadas, las piezas vidriadas tradicionales de Faro, así como otros elementos nuevos como el cristal o los azulejos decorados, éstos últimos más comunes a partir del siglo XVII. Hay que destacar la pervivencia de las decoraciones incísas horizontales hasta

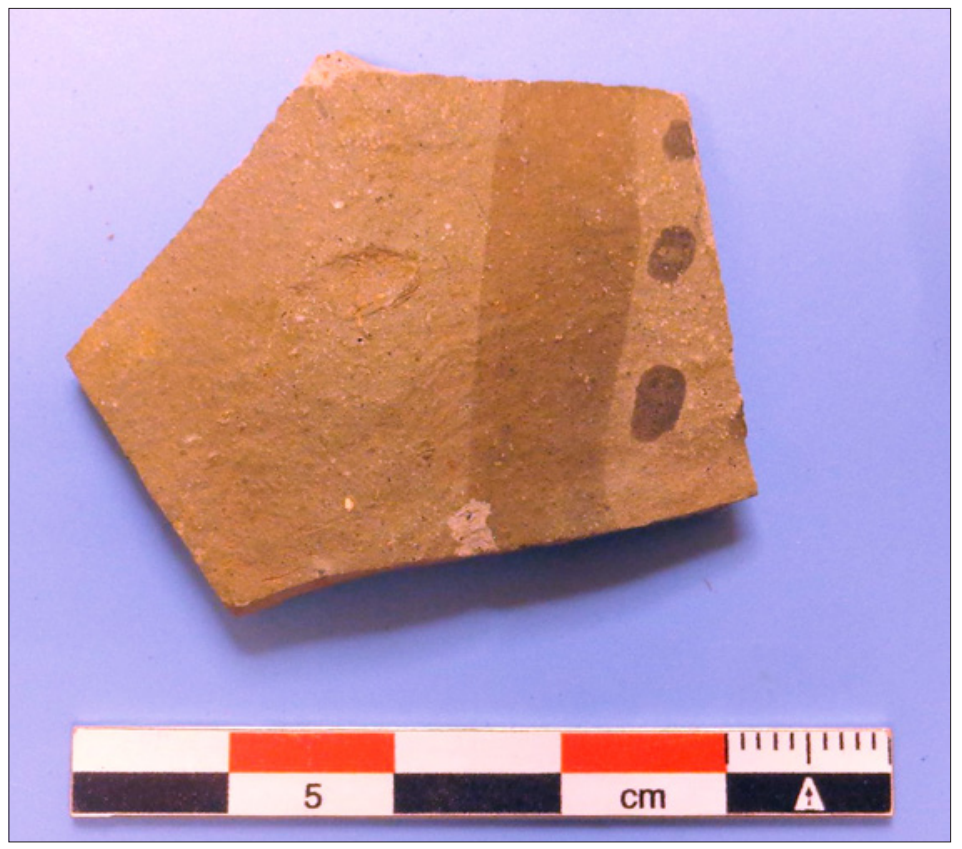

Fig. 3. Pared de una jarra pintada procedente de Miranda en los estratos Bajomedievales de Foncalada (pieza 472, Nivel IIIB - Cata 4). el siglo XVII en algunas ollas, quedando la decoración a punzón relegada a algún borde, mientras que las decoraciones incísas verticales se consideran excepcionales en el siglo $\mathrm{XVI}$. En cuanto a la cocción, las producciones mixtas se hacen ahora mayoritarias y las producciones reductoras adquieren una gran calidad, con tonos y tacto casi "metálicos".

A partir del siglo XVIII la presencia de lozas y piezas vidriadas se incrementa aún más, con un dominio casi absoluto en la vajilla, de la cerámica tradicional tanto de Faro, como en menor medida de Miranda, Llamas, e incluso algunas producciones leonesas y gallegas. Las lozas finas se incrementan a partir del siglo XIX, época en la que sigue el dominio absoluto de la que conocemos, como cerámica tradicional asturiana en sus diferentes producciones.

\section{Evidencias de la expansión especializada de Miranda en Época Moderna. El solar de la calle San Antonio no 12 , Oviedo}

Presentamos a continuación las cerámicas que hemos podido identificar como producciones del alfar de Miranda, encontradas en la excavación arqueológica llevada a cabo en el solar no 12 de la calle San Antonio de la ciudad de Oviedo. Dicha excavación tuvo lugar en el año 2011 y fue llevada a cabo por Gabinete Arqueológico S.L., a quienes agradecemos las facilidades para la consulta de fondos materiales e informes de dicha excavación.

La calle San Antonio se localiza intramuros de la ciudad de Oviedo, siendo uno de sus ramales más antiguos. Esta vía era conocida con el nombre de Solazogue, denominación que ya aparece en las Ordenanzas de la ciudad del año 1245 y que se mantendría hasta el siglo XVIII, cuando empieza a ser sustituida por la denomina- 
ción de San Antonio, debido a la colocación de una imagen del Santo en una hornacina en la fachada de una de las casas de esta calle.

Los arqueólogos encontraron restos correspondientes al incendio que asoló la ciudad de Oviedo en 1521 y toda la actividad constructiva y reconstructiva que se da a posteriori. Así han constatado como se cierra la Calleja de la Estrecha, que era una prolongación de la Calleja de Transantirso hacia la plazulea de Trascorrales y que discurría por este solar (Alonso et alii 2011, 21-22).

La actuación arqueológica se ejecutó en dos fases, en la primera se realizó una trinchera longitudinal al eje principal del solar, y la segunda consistió en el seguimiento arqueológico de la excavación de las zapatas del edificio. Además, se controlaron arqueológicamente los trabajos que se llevaron a cabo en la trasera del solar. La intervención arqueológica permitió reconstruir la secuencia ocupacional y constructiva del lugar. Existe una primera fase de ocupación medieval, con una estructura de postes anterior a 1521. Así mismo, en un determinado momento, anterior al siglo XVI se constata una obra de vaciado o saneo de la zona, construyéndose posteriormente una medianera que será reformada junto con otras partes de la construcción en los siglos XVII y XVIII. Finalmente, a mediados del siglo XIX se levanta el inmueble del que a día de hoy solo se conserva la fachada. De entre los 289 fragmentos cerámicos hallados en esta excavación (Alonso et alii 2011, 28), hay 32 fragmentos de cerámicas de Miranda. Las unidades estratigráficas con piezas de Miranda son: 1, 2, 3, 5, 15, 27 y 28.

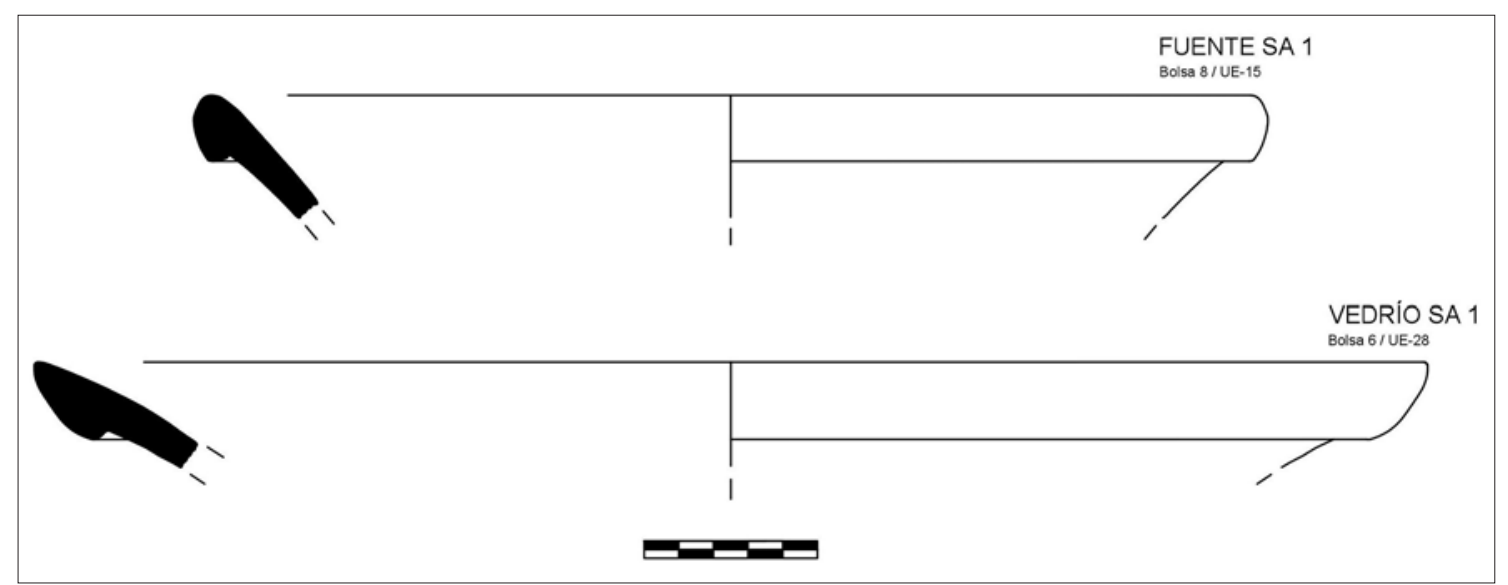

Fig. 4. Tipologías de Miranda. Siglos XVII-XIX.

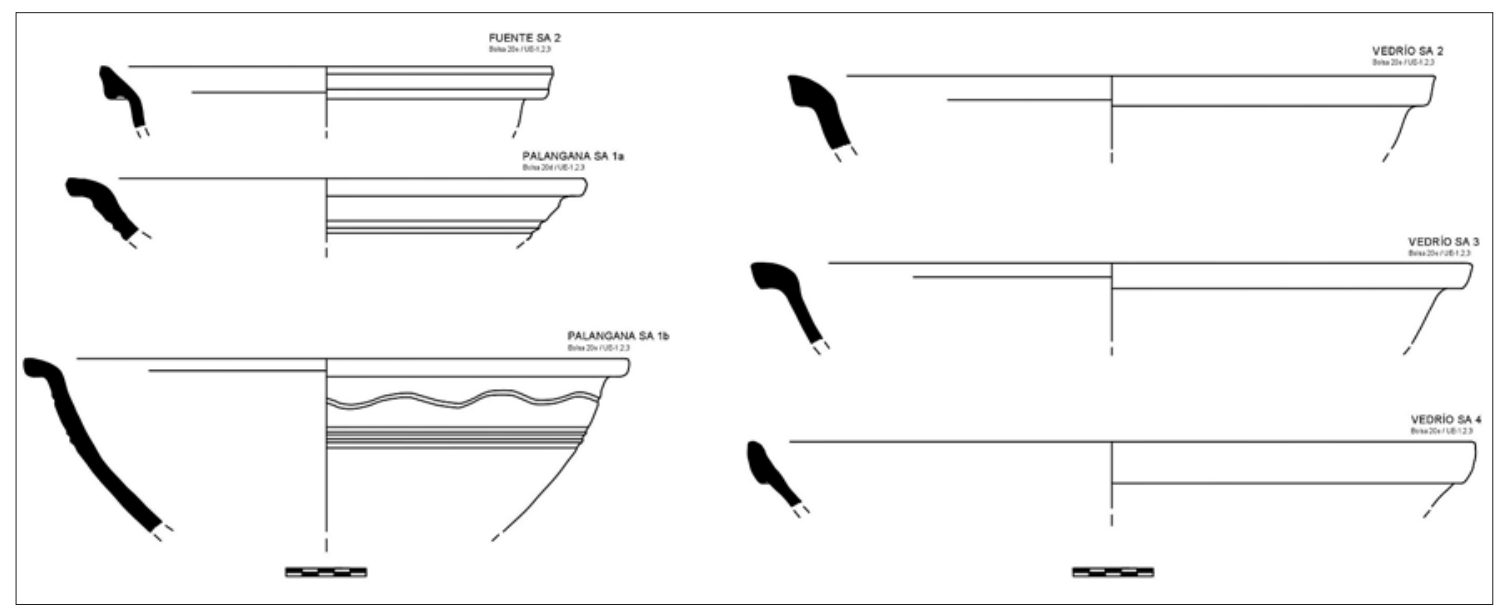

Fig. 5. Tipologías de Miranda, siglos XIX-XXI, fuente, palangana y vedrío. 
A grandes rasgos, podemos diferenciar 3 grupos, el primero de ellos con una cronología circunscrita al siglo XVII. El segundo con un abanico cronológico más amplio dado que se extiende desde el siglo XVII hasta el siglo XIX. El último grupo, parte del siglo XIX y llega hasta el XXI, por lo que se corresponde con la conocida como "cerámica tradicional asturiana". Desde un punto de vista tecnológico, aunque sean producciones con un abanico cronológico muy amplio, poseen unas características comunes, son piezas que han sido elaboradas mediante el torneado de la pieza, la atmósfera de cocción y de postcocción es de tipo reductor, la pasta presenta tonalidades oscuras que van del gris al negro, los desgrasantes son de tipo mediano o fino destacando la presencia de mica y, por último, todas presentan una superficie que ha sido bruñida, otorgándole un acabado brillante.

Las cerámicas de Miranda del grupo del seiscientos han llegado hasta nosotros representadas a través de un único fragmento. Se trata del que hemos denominado Fuente San Antonio 1, que se trata de una forma de borde exvasado, labio redondeado y engrosado que repliega ligeramente, continúa en un cuerpo troncocónico invertido, no se ha conservado la base y no presenta ningún tipo de decoración.
Por el tamaño del diámetro de unos 30 centímetros, hemos considerado este fragmento como fuente, aunque podría tratarse de una fuente de tamaño medio.

El segundo grupo con una cronología que va desde el siglo XVII hasta el XIX, está representado a través del Vedrío (fuente) San Antonio 1. Se trata de una forma con borde exvasado, labio biselado con un cuerpo troncocónico invertido, no se conserva la base ni tampoco las asas que seguro poseía. El vedrío es una de las formas más abundantes y más conocidas de Miranda, lo que hace que también sea la serie cerámica más representada entre los materiales de la Calle San Antonio.

Dentro del tercer grupo, siglos XIX-XXI, entre las tipologías, nos encontramos con la Fuente San Antonio 2, con un borde exvasado, labio engrosado y biselado, que continúa en el cuerpo con tendencia vertical. Otra tipología reconocible ha sido la Palangana San Antonio la y $1 b$, cuya diferencia estriba en el tamaño de su diámetro, siendo una forma muy similar la fuente, se trata de un borde exvasado, proyectado en ala ligeramente al exterior, con un labio engrosado que continúa en un cuerpo globular. Posee una decoración al exterior de una onda incisa bajo el borde y 3 líneas

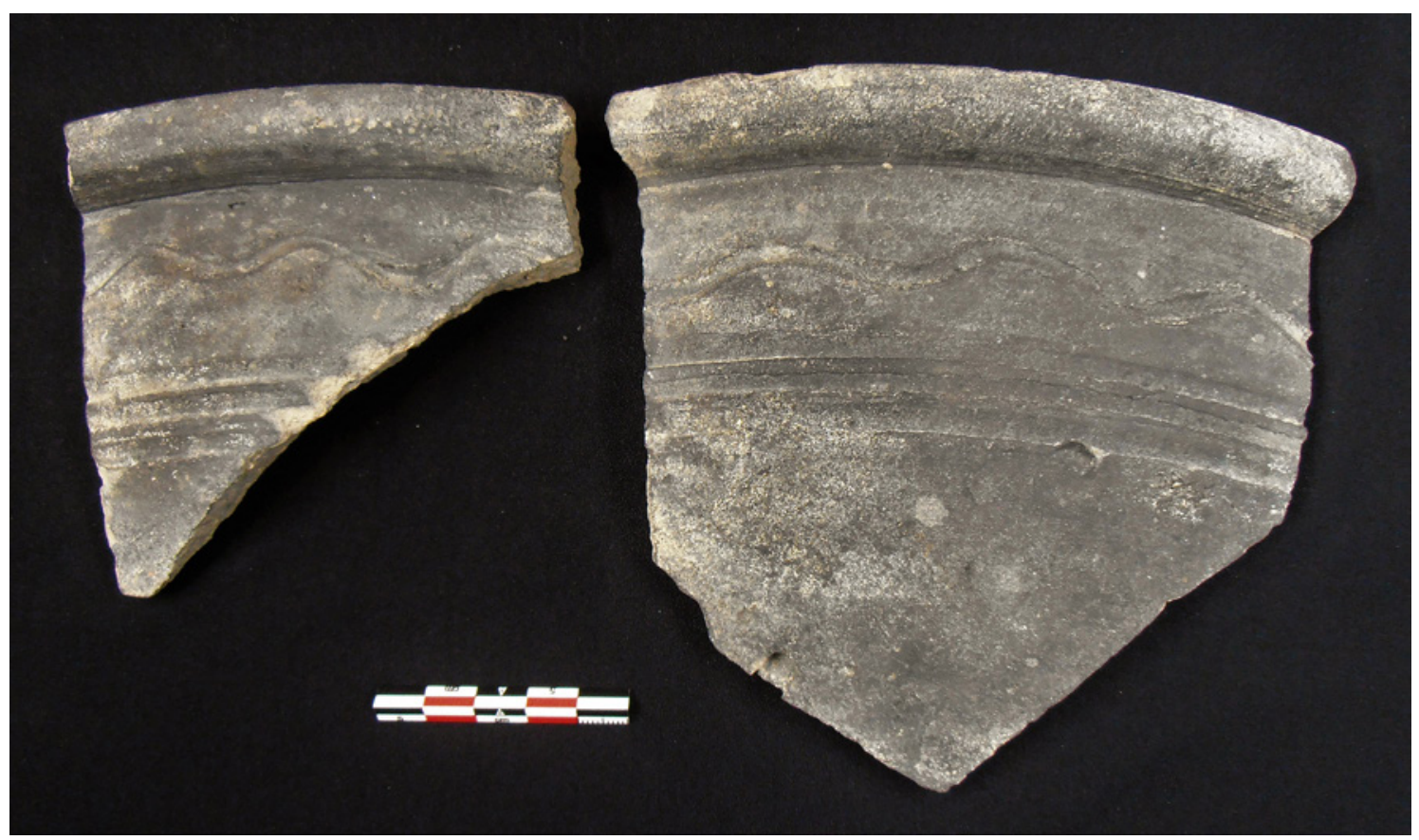

Fig. 6. Palangana San Antonio $1 b$. 
también incisas en la zona media del cuerpo. Creemos que estamos ante una tipología de palangana por su cuerpo globular.

La fuente San Antonio 2, se trata de una forma con un borde exvasado, labio engrosado y biselado, que continúa en un cuerpo troncocónico invertido. Por su parte la fuente San Antonio 3, posee las mismas características morfológicas, solo que con unos grosores menores. El último tipo es la fuente San Antonio 4 con un borde exvasado, labio biselado y cuerpo troncocónico invertido. Además de estas formas, hemos identificado un fragmento de lo que hemos llamado Tonel San Antonio 1, aunque lamentablemente es tan solo un fragmento de cuello, por lo que no podemos saber cómo se desarrollaría la forma. Muy probablemente se trataba de un borde recto con labio redondeado, que continuaba en un cuello de perfil trococónico, que es el que se ha conservado, con una acanaladura, que se unía a un cuerpo ovoide con botón en los extremos. Por otro lado tenemos una base del Bacín San Antonio 1, que conserva las paredes rectas que terminan en una base de tipo plano con huellas de haber sido retorneada. Por último un tipo dentro de la cerámica de servicio y consumo de alimentos, la Jarrita San Antonio 1 con un borde vertical ligeramente exvasado y labio redondeado que continúa en un vano vertical y un cuerpo globular que apenas se conserva, finaliza en una base plana con un acabado retorneado.
Como hemos visto, en los 2 primeros grupos, solo hemos atestiguado la forma cerámica de la fuente. Es en el tercer grupo, de una cronología que se extiende desde el siglo XIX hasta el XXI, cuando vemos que estas formas se mantienen y la fuente sigue siendo la forma más común. A estas series se le unen la palangana, el bacín (bacinilla), el tonel y la jarrita. Este hecho puede indicarnos el aumento de la producción cerámica en Miranda de una manera mucho más diversificada, al mismo tiempo que puede señalarnos la necesidad y demanda por parte de la sociedad asturiana de nuevas formas cerámicas para satisfacer nuevas necesidades que o bien con anterioridad no existían o eran satisfechas con la utilización de otro tipo de menaje cómo puede ser el lígneo (Busto Zapico, 2015, 62).

\section{Posibles evidencias de su difusión Postmedieval en el Noroeste. Cerámi- ca de Miranda en Santiago de Com- postela}

En la rúa do Franco n³1, dentro del antiguo recinto defensivo de la ciudad de Santiago de Compostela, con motivo del acondicionamiento para un local de hostelería se realizan obras, que llevan parejas labores de arqueología preventiva. En dos excavaciones diferentes, la primera dirigida por Manuela Pérez Mato y la segunda por Álvaro Rodríguez Resino. Será durante la segunda intervención (Rodríguez

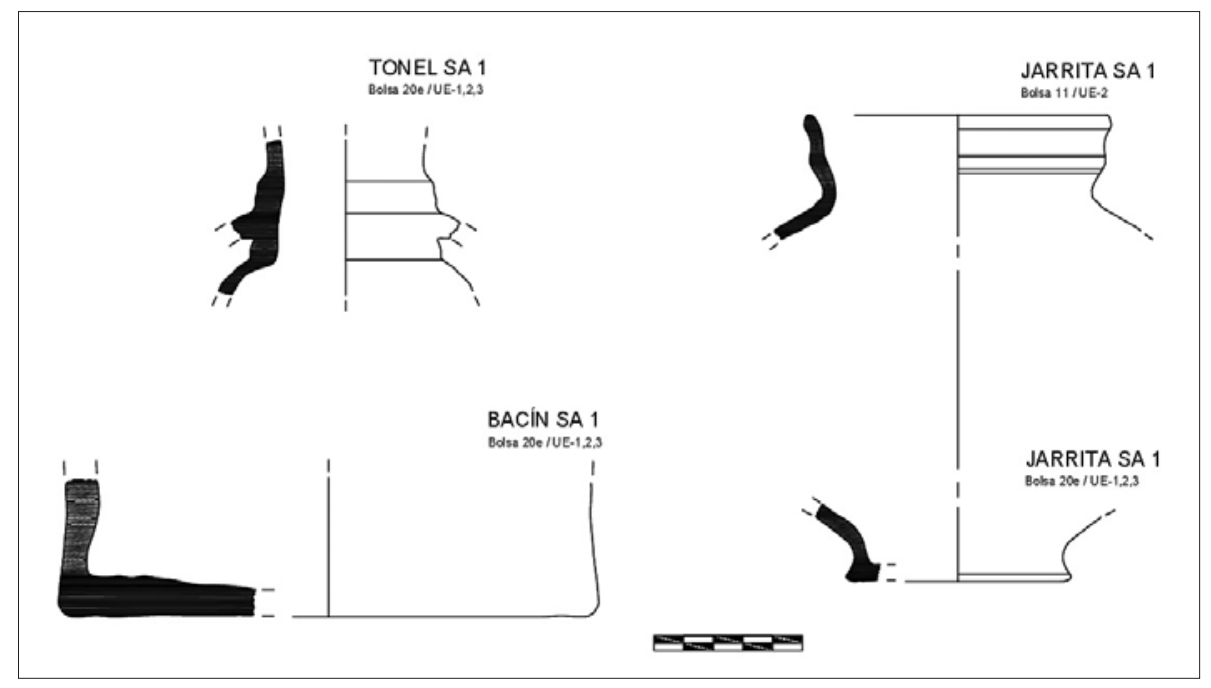

Fig. 7. Tipologías de Miranda, siglos XIX-XXI, tonel, bacín y jarrita. 
Resino 2012), cuando aparecerán los posibles fragmentos de cerámica de Miranda a los que nos referiremos más adelante. Estas intervenciones evidenciaron un potente relleno de cronología moderna y contemporánea, que cubrían el arco de acceso a una torre urbana de cronología medieval así como un pozo y soportal modernos, amortizados en el siglo XIX, con la construcción de la fachada actual que da a la rúa del Franco (Alonso Toucido et alii 2013, 216). De una fase anterior a la edificación medieval, se documentaron un conjunto de fosas excavadas en el substrato algunas de gran tamaño de entre 4 y 6 metros cúbicos. Estas fosas han sido interpretadas como lugares de almacenamiento, tanto de cereal (las más grandes), como de fruta, verduras o productos lácteos, las más pequeñas (Rodríguez Resino 2013:201). Este tipo de estructuras, tanto por la cerámica gris medieval documentada en ellas, como por las dataciones absolutas practicadas en sus sedimentos, han sido datadas en época plenomedieval (Alonso y Prieto 2016).

La posible cerámica de Miranda documentada, ha sido localizada en estratos pertenecientes a la Edad Moderna. Tanto en la limpieza de la mayor fosa medieval, en un sedimento removido y posiblemente caído dentro de la misma durante los trabajos de obra (UE20), por tanto no se descarta que entre los materiales recuperados en la intervención de Manuela Mato, pueda haber producciones de similares características. Otra de las UEs en las que se evidenció este tipo de cerámica es la UE 100 la cual se corresponde con la colmatación de un pozo de forma cuadrangular en cuyas paredes se localizaron huecos para asentar peldaños de bajada. Lamentablemente la excavación del pozo tuvo que paralizarse a dos metros, por motivos de seguridad y salud, ante las continuas filtraciones de aguas negras.

A nivel cronológico, estas dos UEs se encuadran en época moderna, tanto por sus materiales cerámicos como numismáticos, en la UE 20 se localizó un conjunto de 3 maravedís de vellón, uno de ellos con recuño de
1652. La cerámica de la UE 20 es coherente con esta datación, presentando tanto cerámica común como piezas de lujo en forma de faiança portuguesa (Alonso et alii 2013, 234). En cuanto a la UE 100 a pesar de no contar con indicadores numismáticos, esta sí que aporta una pieza de cerámica de Talavera de la Reina, de la serie "orla castellana", documentada en intervenciones con cronología del siglo XVII, en Santiago de Compostela (Castro Lorenzo 2009, 146 y Parga 2013: Anexo 1, 26), por tanto es posible que ambas UEs sean coetáneas.

En cuanto a la posible cerámica de Miranda de estas dos UEs, son 6 los recipientes a los que se les ha dado esta posible adscripción (Con números 29, 44, 45, 47, 66 y 67).

No 29: Dos fragmentos, asa y base (REF/20/04 y 15 respectivamente), recipiente de perfil troncocónico, con base de reducido diámetro $(6 \mathrm{~cm})$ y cuerpos globulares con paredes relativamente finas de entre 4 y $8 \mathrm{~mm}$. El asa es de cinta y una anchura de $44 \mathrm{~mm}$. A nivel decorativo destacan unas líneas bruñidas verticales en su cuerpo y asa así como en esta última, líneas acanaladas y 5 punzados que no llegan a atravesar toda su pared. En cuanto al tratamiento de sus pastas, el acabado exterior es negruzco, mientras que la fractura cuenta con una transición del gris al rojizo, presentando un tratamiento de las mismas cuidado, con escaso desgrasante en forma de fragmentos de mica y cuarzo de muy reducido tamaño.

No 44: Fragmento de base (REF/20/38) con ligera concavidad, un diámetro de $9 \mathrm{~cm}$ y un grosor de sus paredes de $6 \mathrm{~mm}$. Sus pastas de color grisáceo en el exterior y con un tono gris amarronado en la fractura, presentan desgrasantes de mica y cuarzo; con una cantidad escasa. El perfil del recipiente es desconocido.

No 45: Dos fragmentos de cuerpo (REF/20/02 y 50), con unas marcas interiores de torneado muy marcadas y un grosor de 6 a $4 \mathrm{~mm}$. En el exterior sus pastas son de color negruzco mientras que presentan una fractura gris con abundante desgrasante de mica y cuarzo. Su morfología es desconocida. 


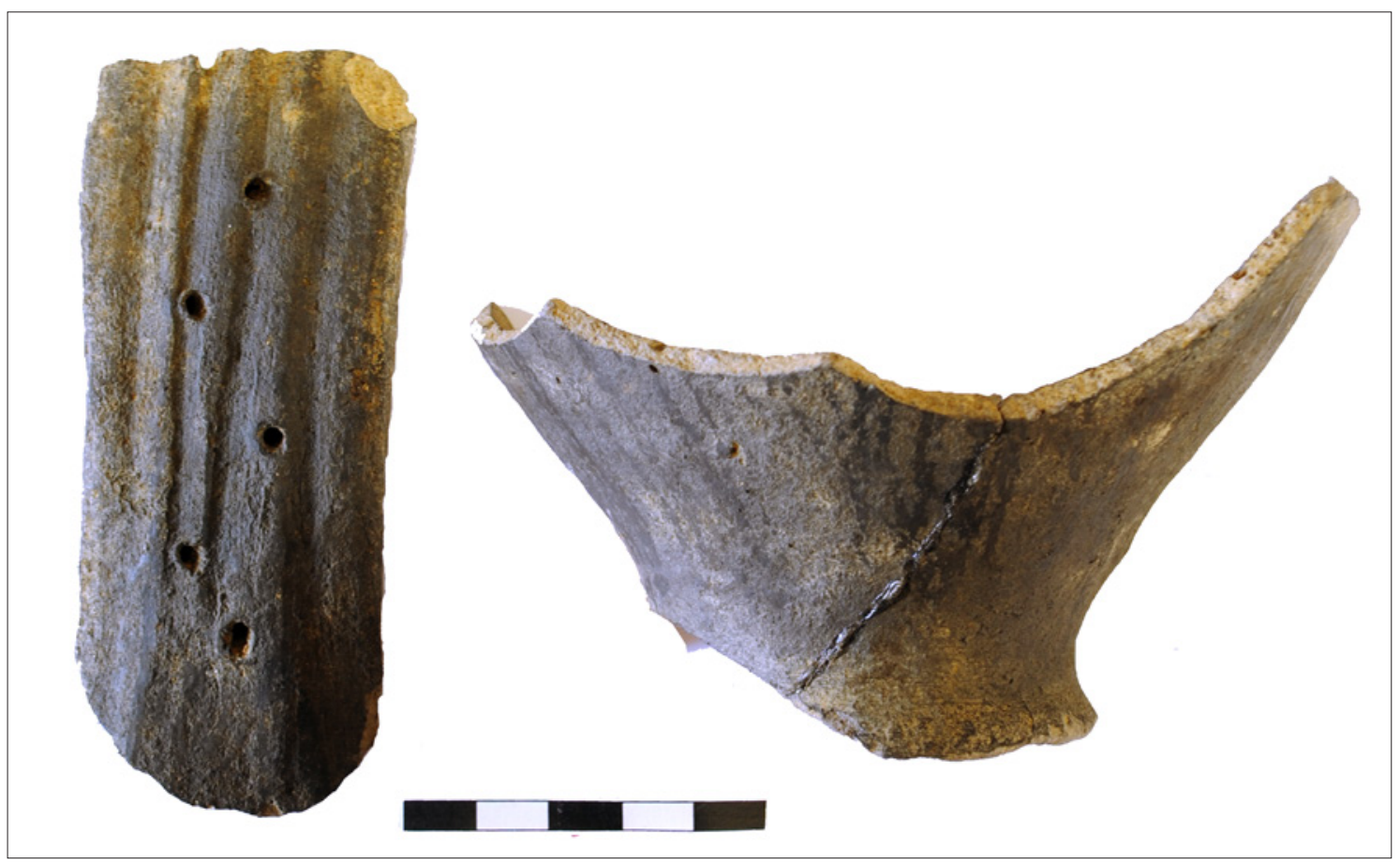

Fig. 8. Piezas número 67 y 44.

No 47: Tres fragmentos de borde y uno de cuerpo (REF/100/002, 014, 015 y 07 respectivamente) pertenecientes a una forma abierta de gran tamaño, $60 \mathrm{~cm}$ de diámetro y hasta 12 $\mathrm{mm}$ de grosor. El borde es exvasado, convexo con engrosamiento y labio redondeado. Su superficie exterior se encuentra espatulada a la vez que bruñida, siendo de un color negro intenso. La pasta de sus fracturas cuenta con desgrasante de mica y cuarzo así como partículas negras, no identificadas.

No 66: Fragmento de borde (REF/20/19) de forma desconocida que presenta acanalados en sus paredes. Su superficie interior y exterior se encuentran bruñidas poseyendo un color negro, mientras que sus pastas son de tonos grises con desgrasantes de cuarzo y mica así como el elemento negro indeterminado también identificado en el n47.
No 67: Fragmento de asa (REF/20/18) con sección ovalada. Su superficie exterior es negra, mientras que el interior cuenta con una tonalidad rojiza. A nivel de desgrasante presenta cuarzo y mica mientras que en una órbita decorativa cuenta con un punzado en su centro, que no llega a perforar completamente la pieza.

Las piezas que acabamos de describir cuentan con morfologías variadas y por el momento desconocidas en Galicia. Su homogeneidad vendrá en el tratamiento de sus acabados y pastas caracterizándose por los acabados bruñidos y coloración de tonos negruzcos en sus exteriores mientras que en el interior serán grisáceos con transición al rojo en alguno de los recipientes o gris simplemente. El desgrasante salvo la excepción del elemento negro, presente en dos recipientes, está formado mayoritariamente por cuarzo y mica.

Fig. 9. Pieza número 66.

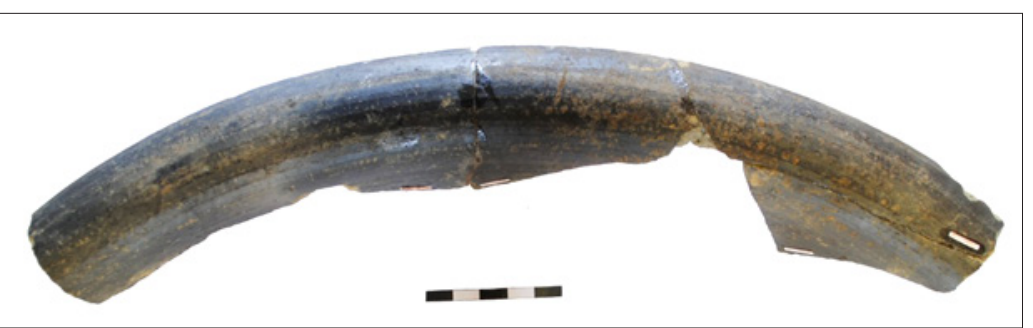




\section{Conclusiones}

A diferencia de otros alfares asturianos como Faro (Fanjul 2017) o Llamas del Mouro (Fanjul y Tobalina 2016) donde la revisión de los orígenes de sus producciones tradicionales, se ha realizado mediante la excavación arqueológica y el soporte cronológico aportado por los análisis de carbono 14, en el caso de Miranda hemos escogido la revisión directa de colecciones materiales bien estudiadas, procedentes de diversas actuaciones arqueológicas en contextos urbanos de Oviedo y de Santiago de Compostela.

Los datos aportados por las tres excavaciones analizadas, nos permiten certificar dos aspectos tratados previamente por otros investigadores pero que hasta el momento carecían de una comprobación arqueológica. Por un lado al igual que en el caso de Llamas del Mouro, existe una Miranda anterior a las producciones tradicionales, que como sostenía Feito (1985) para el caso avilesino, parece remontarse a la Baja Edad Media, con una difusión de sus productos en un ámbito local, y unos productos finos de mesa, dentro del binomio jarra/olla característico de la vajilla medieval.

Por otra parte, hemos observado como los estudios documentales que remitían a las producciones de Miranda tradicionales al siglo XVI (Heredia 2008), se corresponden con las piezas estudiadas en las diferentes excavaciones demostrando que la cerámica tradicional de Miranda surge en este siglo.

En lo que se refiere a la excavación de Foncalada la presencia de piezas cerámicas de Miranda en Oviedo esta constatada desde los siglos XIII-XV, con materiales escasos y peculiares como puede ser la pieza pintada no 472. A partir de ese momento se observa un incremento paulatino de la producción de Miranda en Oviedo con la excepción del siglo XVIII, donde debido quizás a la potente competencia de las lozas y de las producciones vidriadas locales, Miranda apenas tiene representación en la vajilla doméstica ovetense. En el siglo XIX sin embargo, Miranda tiene una destacada presencia gracias a piezas especializadas y de gran éxito comercial como son las fuentes y toneles.

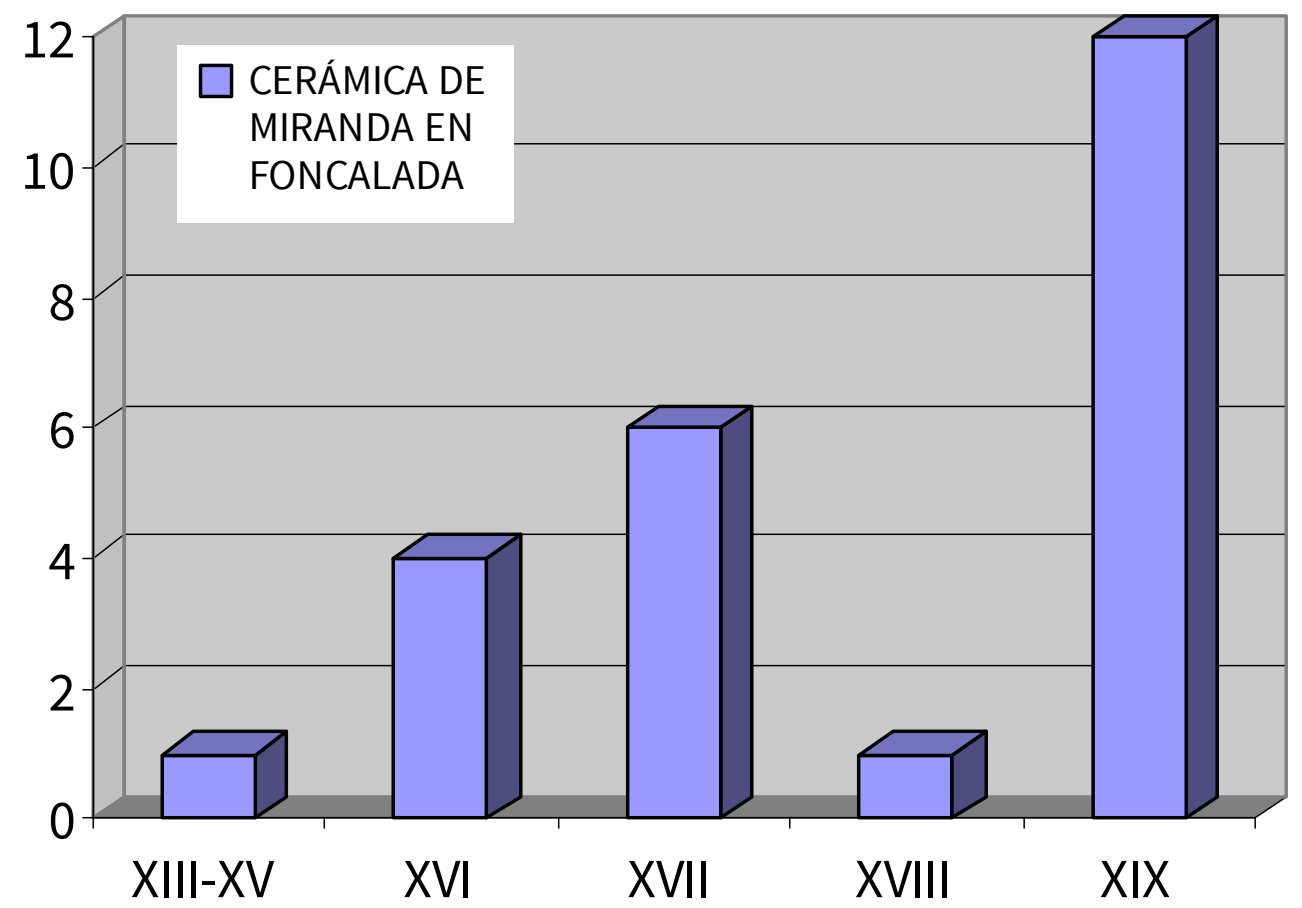

Tabla 1. Evolución cronológica de la cantidad de piezas de Miranda en el registro estratigráfico de Foncalada. 
En la excavación de la calle San Antonio no 12 de Oviedo hay trazas arqueológicas del incendio de la ciudad de Oviedo de 1521 (Alonso et alii 2011, 6-20), pero ni en las UEs relacionadas con este incendio, ni en las más antiguas encontradas en el solar hay restos cerámicos que podamos identificar con producciones de Miranda. Este hecho, hace hincapié en la idea de que la producción de cerámica tradicional en Miranda comenzaría a finales del siglo XVI, nunca antes de 1521.

En el siglo XVIII y con anterioridad en Miranda la producción de cerámica doméstica, muy probablemente se limitaba a muy pocas series, entre las que destacaba por encima de todas ellas la fuente, cuya funcionalidad no podemos desligar de un posible uso constructivo dado que podría utilizarse como un recipiente idóneo para la elaboración de morteros (Busto Zapico, 2015, 55, nota 76).

A partir del siglo XVIII, asistimos a un aumento en la variedad de las formas de cerámica domésticas elaboradas en Miranda, que debemos explicar por un aumento de la demanda y de la aparición de nuevas necesidades culinarias, almacenamiento, higiéne... en la sociedad asturiana, lo que lleva aparejado la creación de nuevos útiles domésticos (Busto Zapico, 2015, 60-64).

Finalmente los datos arqueológicos procedentes de Santiago de Compostela refuerzan los datos documentales estudiados por Heredia (2008), a través de los que se observa una relación directa al renacimiento de la cerámica de Miranda en el siglo XVI, convertida ya en la cerámica tradicional que llega hasta el siglo $X X$, y su expansión comercial inter-regional durante la Época Moderna.

\section{Referencias bibliográficas}

ALONSO TOUCIDO F., PRIETO MARTÍNEZ M.P. (2016): Franco no31 (Santiago de Compostela), una nueva datación para la arqueología medieval de la ciudad. Poster presentado en las 'VI Jornadas de Arqueologia do Vale do Douro. Do Paleolítico à Idade Média'. Porto, 17-19 de novembro de 2016.

ALONSO RODRÍGUEZ, Nicolás., JIMÉNEZ CHAPARRO, Jesús Ignacio y REQUEJO, Otilia (2011): Informe de las excavaciones en el solar de la calle San Antonio 12. Oviedo.

ALONSO, F.; PRIETO, M.P., RODRÍGUEZ, A., (2013): “Cerámica en silos. Contextos medievais e modernos na rúa do Franco" no 31, Gallaecia 32: 215-248.

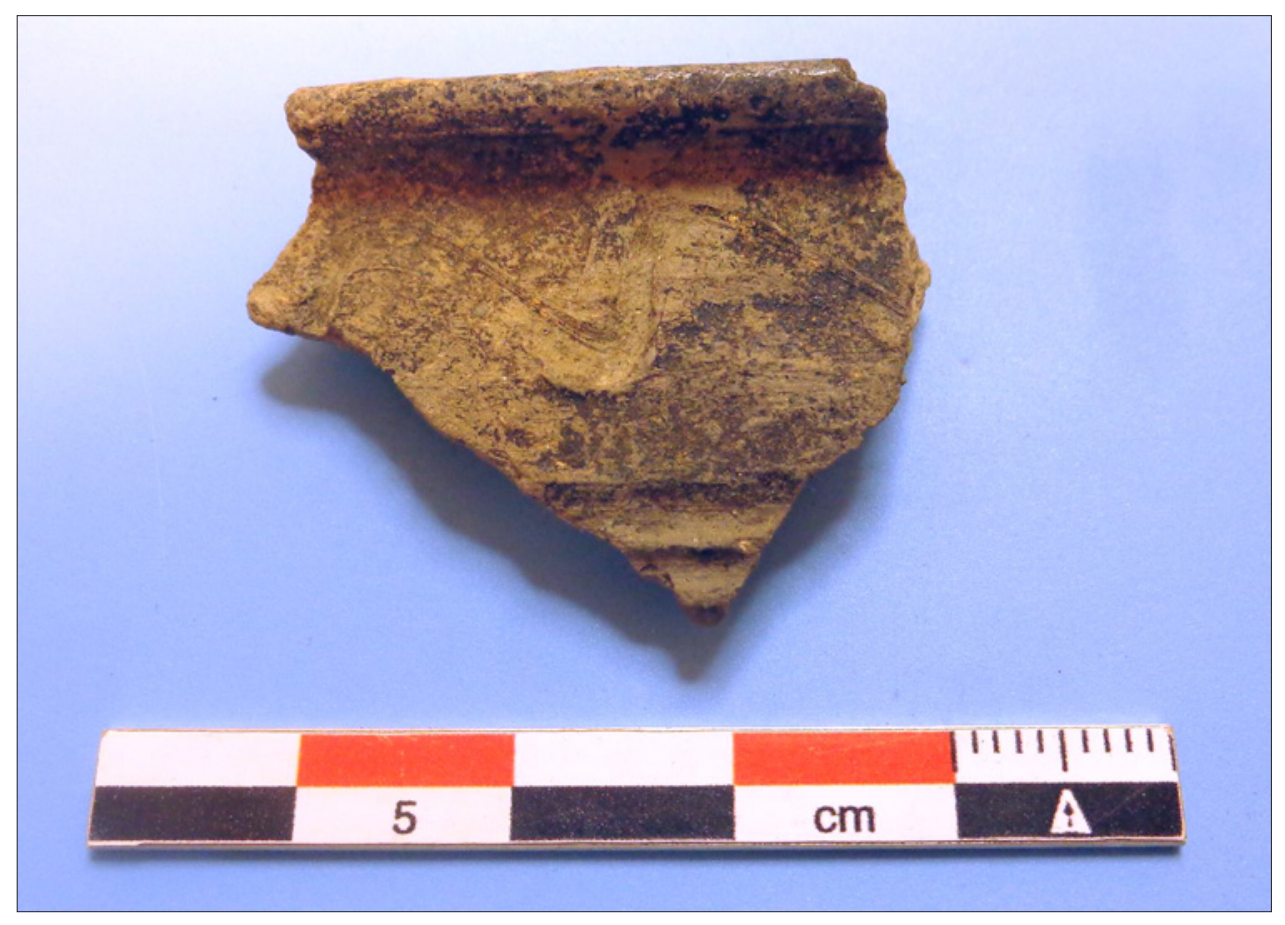

Fig. 10. Fragmento de olla baja de Miranda decorada con onda gruesa y línea incisa horizontal, con una cronología del siglo XVII (pieza 520, Nivel IIB - Sector A5). 
BUSTO ZAPICO, Manuel. (2015): “Cerámica de producción local en Asturias entre los siglos XVI y XVII procedente de la excavación de la casa Carvajal Solís (Oviedo, Asturias)". Boletín de letras del real instituto de estudios asturianos, 185-186: 33-64.

CASTRO LORENZO, M. L. (2009): "La vajilla de lujo en Santiago de Compostela en los siglos XVI y XVII: aportaciones de la arqueología". Revista de Estudios Provinciais, 22: 123-158.

ESTRADA, Rogelio y RIOS, Sergio. (1995): "Excavaciones arqueológicas en la plaza de la Foncalada (Oviedo) 1991-1994". Excavaciones arqueológicas en Asturias 1991-1994: 138-146.

FANJUL PERAZA, Alfonso. (2017): Orixe y desendolcu de la cerámica de Faro. Gijón.

FANJUL PERAZA, Alfonso. (2013): "Ethnoarchaeology of the Narcea valley: New Data on the Origins of Llamas del Mouro Ceramics (Asturias, Spain)" Trébole. Boletín cultural de Asturias en USA, 1: 11-16.

FAN JUL PERAZA, A. y GARCÍA ALVAREZ-BUSTO, A. (2008): "Etnoarqueología cerámica. Algunos apuntes sobre las producciones asturianas tradicionales a través de la arqueología urbana". Lancia. 7. Universidad de León: 157-167.

FANJUL PERAZA, Alfonso y TOBALINA PULIDO, Leticia. (2016): "En torno al origen y la evolución de la cerámica de Llamas del Mouro (Cangas del Narcea). Excavaciones arqueológicas en Casa Celista”. Asturies, 36: 68-80.
FANJUL PERAZA, A., TOBALINA PULIDO, L., RUIZ DE ARBULO, I., AREVALO MUÑOZ, E., CAMARERO ARRIBAS, C., HERRERA MACEIRAS, S. \& TRIACHINI, Y. (2013): "The medieval origins of Faro ceramics (Oviedo, Spain). Excavations at Cantu L' Rey". Medieval pottery research group. Newsletter, 75. March 2013: 3.

FEITO, José Manuel. (1985): Cerámica tradicional asturiana. Oviedo.

HEREDIA ALONSO, Cristina (2008): "La traida de aguas del barrio avilesino de Sabugo. Traza y obra de Pedro de la Bárcena". Liño, 14: 22-33.

PARGA CASTRO, A. (2013): Actuaciones arqueológicas en la avenida de Raxoi (Santiago de Compostela). Memoria técnica e interpretativa. Memoria Inédita depositada Concello de Santiago de Compostela. Santiago de Compostela.

RODRÍGUEZ RESINO, A. (2012): Memoria final da excavación en área do solar da rúa do Franco 31. Santiago de Compostela. Santiago de Compostela. Memoria Inédita depositada en el Concello de Santiago de Compostela.

RODRIGUEZ RESINO, A. (2013): "Sistemas subterráneos de almacenamiento en la Galicia medieval. Una primera tipología y consideraciones para su estudio". En A.

VIGIL, G. BIANCHI e J. A. QUIRÓS (eds.), (2008): Horrea, barns and silos. Storage and incomes in Early Medieval Europe Argitarapen Zerbitzua: 193-208. 